\title{
IS OPEN SOURCE GIS FEASIBLE IN MILITARY OPERATIONS? EVALUATION BY APPLYING A USE CASE
}

\author{
Susan Henrico, ${ }^{1}$ Stellenbosch University \\ Serena Coetzee, ${ }^{2}$ University of Pretoria \\ Antony Cooper, ${ }^{3}$ University of Pretoria and Smart Places, CSIR
}

\begin{abstract}
The study of terrain and all its related elements and facets are of crucial importance to the military, with the importance of terrain being recognised by military leaders more than two thousand years ago. Military operations can occur at any of the three levels of war: tactical, operational and strategic, and can be a combat operation or a military operation other than war (MOOTW). Information about the geography empowers a military commander to plan and execute a mission successfully. As technology developed and evolved, geographic information systems (GIS) have come to play a major role in this. Today, a military operation without the use of GIS is unthinkable. In a developing country like the South Africa, however, licenses for proprietary GIS software, vendor-exclusive training and the bureaucracy of the procurement cycle add to the time and costs of a mission. The question arises whether open source software is a feasible alternative. Since the South African National Defence Force was initially trained in the use of proprietary software and it therefore became a strong habit, the perception now exits that Free and Open Source Geographic Information Software (FOSSGIS) products are neither mature enough nor user-friendly enough to be used in military operations. This study evaluated the use of an open source desktop GIS product, QGIS, in a use case for MOOTW. QGIS, outputs were compared to those produced in ArcGIS, a proprietary desktop GIS product developed by Esri, widely used in military operations. The user-friendliness of the two products as well as pricing was also compared. Results show that the QGIS outputs provide the operational commander with equivalent information to plan and execute a mission successfully. This implies that open source GIS is suitable for military operations, especially those with limited budgets and at short notice, such as in the case of disaster relief.
\end{abstract}

Keywords: open source software, military operation, geographic information system, QGIS, disaster relief

\section{Introduction}

In recent years, the South African National Defence Force (SANDF) has become involved in a number of military operations other than war (MOOTW). Neethling agrees that, although the military is historically "organised" for their involvement in battles on land, in the air or at sea, their scope has been expanded "to include assistance (also to other countries) in cases of natural disaster; participation in peace-support 
operations; support to police forces in upholding law and order; and a role in socioeconomic development". 4,5

In this study, a use case was therefore developed in the form of an outbreak of cholera in the Pilanesberg area. The outbreak of this highly infectious disease is a very realistic scenario in a developing country such as South Africa, where sanitation problems often occur. The understanding of the terrain remains essential for planning operations even in the MOOTW role. The layout of the terrain influences the execution time of certain manoeuvres or operations, ${ }^{6}, 7$ and even communications are influenced by the terrain. Amongst others, line of sight, vegetation, topography, hydrology and human presence in the terrain and its surroundings need to be considered. Using geographic information systems (GIS) to analyse and visualise geospatial information develops an understanding of the terrain. ${ }^{8}$

GIS has become a requirement rather than just an advantage for militaries. Availability and access to GIS software and geospatial information are therefore imperative. Proprietary software, the bureaucracy of the procurement cycle, the cost of acquiring and maintaining software licenses, as well as vendor-exclusive training of staff in the use of the software constrain the availability of and access to GIS, thereby having the potential to reduce possible benefits of such a system to the military. By using open source software, these constraints can be eliminated. With open source software, the source code is openly shared, and new tools are often developed at a much quicker pace than in the case of proprietary software products since the development cycles are different. More advanced GIS tools can for instance be downloaded without the burden of additional costs. In the international geospatial community, the last decade has seen an increase in the development and implementation of GIS based on open source GIS software. ${ }^{9},{ }^{10},{ }^{11}$

However, in military communities, the perception seems to exist that open source GIS are neither user-friendly nor mature enough to be used in military operations. This perception is based on discussions with colleagues and many years of experience in a defence force environment, where the proposal to introduce open source GIS was met with hesitance and even resistance. The aim of this article is to demonstrate the use of an open source GIS product as a feasible alternative in military operations.

\section{Methodology}

A literature review provided insight into the precise role of geospatial information in the military, the three levels of war (strategic, operational, and tactical) and the use of GIS on each of these levels. ${ }^{12},{ }^{13},{ }^{14},{ }^{15},{ }^{16}$ Based on this, a use case of a military operation was developed and typical GIS outputs required by the operational commander were identified. The GIS outputs were prepared in QGIS $^{17}$ (version 2.8.5-Wien), an open source desktop GIS product, and compared to the same outputs prepared in ArcGIS ${ }^{18}$ (version 10.2), a proprietary product widely used in military, serving as the baseline.

Other research has compared ArcGIS to QGIS, ${ }^{19},{ }^{20},{ }^{21}$ and there are examples of humanitarian operations using open source geospatial data and software, such as the Humanitarian OpenStreetMap Team (HOT). ${ }^{22}$ The study reported in this article was unique, because it incorporated military operational requirements. The aim was not to 
find a 'victor' in a competition, but rather to present the results of an objective study on the feasibility of open source GIS in a military operation use case.

The use case created for this study required specific GIS outputs (Tests 1 to 7 , see use case). However, this study only performed Test 1 (hill shading), Test 2 (flood simulation) and Test 3 (mapping of existing infrastructure), because Test 4 (buffering an area of operation), Test 5 (hot spot analysis), Test 6 (creating a visibility layer) and Test 7 (creating a water purification plants layer) were compared in an earlier study. ${ }^{23}$ A comparison of user-friendliness and costs are included in this article. The article is concluded with a discussion of results and conclusions.

\section{Data collection and analysis based on the use case}

TomTom Africa supplied the vector data, as well as the $20 \mathrm{~m}$ digital elevation model (DEM) for the study area. ${ }^{24}$ The DEM was used to produce the required hill shading product and the angles for the light source (the sun) were set to an azimuth of $315^{\circ}$ (i.e. degree distance measured clockwise from north at $0^{\circ}$ ) and an altitude of $45^{\circ}$ (i.e. angle above the horizon). The remaining data were obtained from National Geo-spatial Information (NGI) ${ }^{25}$ a component of the South African Department of Rural Development and Land Reform (DRDLR). All data were defined and projected to WGS84/UTM grid zone 35S. The data used in this study were:

- a clipped vector data set of roads, rivers, railway lines, water bodies, built-up areas and points of interest;

- $\quad$ a subset of the SPOT6 image and 1:50 000 raster topographical maps; and

- $\quad$ a $20 \mathrm{~m}$ digital elevation model in GeoTIFF format. ${ }^{26}$

The data were used to create the required GIS products by using both QGIS and ArcGIS, and the results were analysed by comparing the different products. ArcGIS is widely used in military operations and therefore served as the baseline against which to compare the QGIS results.

\section{Study area}

As stated previously, the Pilanesberg area, located in South Africa, was chosen as the study area (see Figure 1). An interesting fact about this area is that it is set in an alkaline ring complex, and it is one of only three such complexes in the world. The terrain setting is perfect for a demonstration of the involvement of the military in a MOOTW, since it is a mountainous area (which can make military communications and manoeuvrability difficult) and yet it is close to a settlement of people (where the spread of an infectious disease, such as cholera, can quickly escalate). 


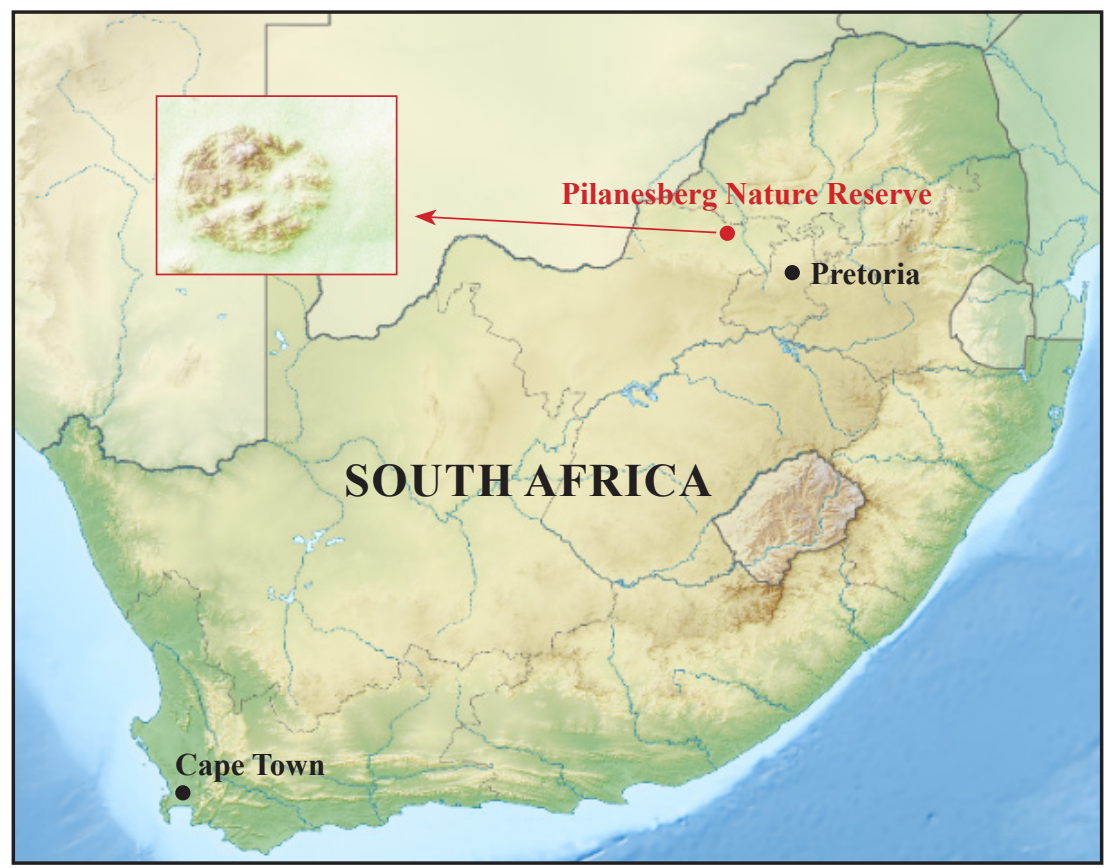

Figure 1: Study area - Pilanesberg, South Africa

\section{Use case: A cholera outbreak in Pilanesberg area, South Africa}

Cholera still affects many parts of the world today and is caused by drinking or eating contaminated water or food. It is often found in areas with "poor sanitation, crowding, war, and famine". "If left untreated, it can lead to death". ${ }^{27}$ After consultation with commanders involved at different levels and in different roles in operations, ${ }^{28},{ }^{29},{ }^{30},{ }^{31}$ a use case was developed that describes the health risk disaster relief operation in response to a cholera outbreak in the Pilanesberg area of South Africa.

The use case (presented as a fictional operational tasking) describes the GIS outputs typically required for such a military operation in the SANDF:

Because the SANDF is the only national entity with a suitable medical deployment unit capability, the Ministry of Health requests the SANDF to assist in curbing the outbreak of cholera in the rural population of the Pilanesberg area in the North-West, a province of South Africa. The commander in charge of the operation is tasked with setting up an operations room in the disaster management centre and deploying the following to manage and control the outbreak: a medical post with doctors and nurses; two infantry companies responsible for barricading and securing the contaminated area; and a squadron for installing and running water purification units. The operational commander requires the following GIS outputs to plan and execute this mission: 
Test 1 - an analyse of the terrain is required, such as planning routes and selecting suitable vehicles for the terrain, so that logistics can be planned. A hill shading is required. A hill shading is a 3D view of the terrain that reveals differences in slope and height by taking into account the illumination source angle and shadows.

Test 2 - cholera spreads through contaminated water and therefore heavy rains pose a risk. A flood simulation layer is required to anticipate the influence on the spread of cholera, should water levels rise.

Test 3 - finally, a map of the area of operations and surroundings is required that shows existing infrastructure, such as roads, helipads, schools, hospitals and police stations. This map will be used to identify suitable locations for the operational headquarters (HQ), medical post, entry/exit roadblocks and helicopter landing zones.

Test 4 - the individual households reported as households with cholera were digitised by using the Spot 6 image as backdrop in order to zoom in on the residential areas. An area of $10 \mathrm{~km}$ around the residential areas needs to be demarcated, since this will be the 'area of operations'.

Test 5 - the high-risk cholera areas, i.e. areas with a high density of infections, need to be determined regularly in order to monitor the spread and to plan emergency treatments and evacuations of patients in serious conditions. For this, a hot spot analysis is required.

Test $6-\mathrm{A}$ hill shading is required so that the logistics can be planned. A hill shading is a $3 \mathrm{D}$ view of the terrain that reveals differences in slope and height by taking into account the illumination source angle and shadows.

Test 7 - communications are essential during any military operation. Radio communications work on the principle of 'line-of-sight' and therefore a line-ofsight visibility from the identified HQ and to the rest of the area of operations is required.

\section{Results of GIS outputs based on the use case}

The results of the GIS outputs that were produced from the various tests, as highlighted in the use case, are presented in this section.

Test 1: Hill shading to reveal differences in slope and height

In ArcGIS, the Hillshade tool of the Spatial Analyst extension was used (see Figure 2). In QGIS, the Hillshade tool in the collection of Terrain Analysis tools was used (see Figure 3). Both outputs were suitable for terrain analysis and assisted the commander in developing an operational plan. 


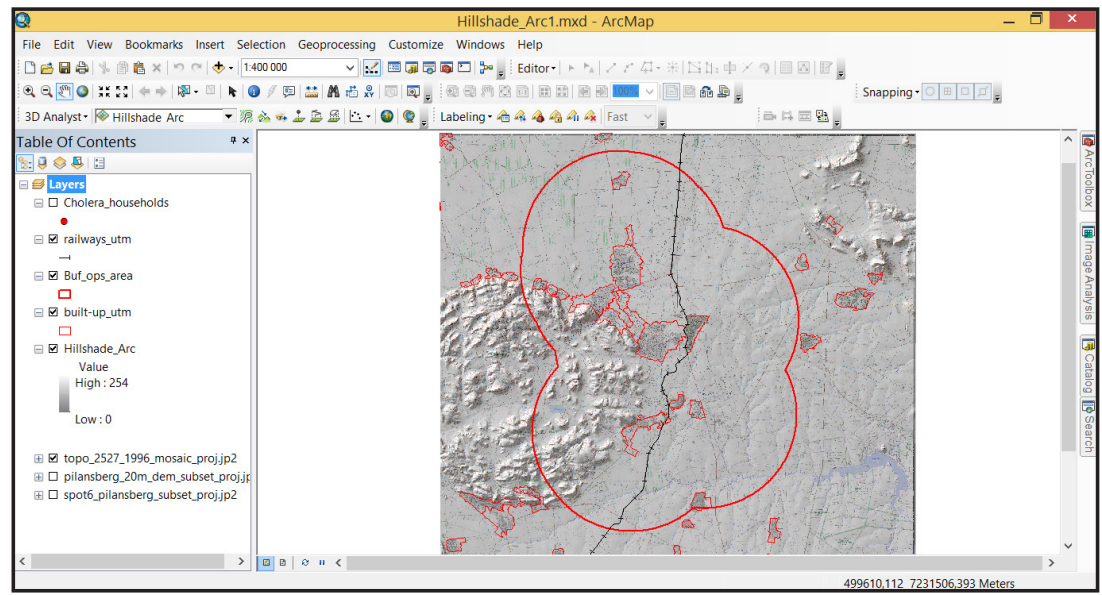

Figure 2: Terrain analysis - ArcGIS

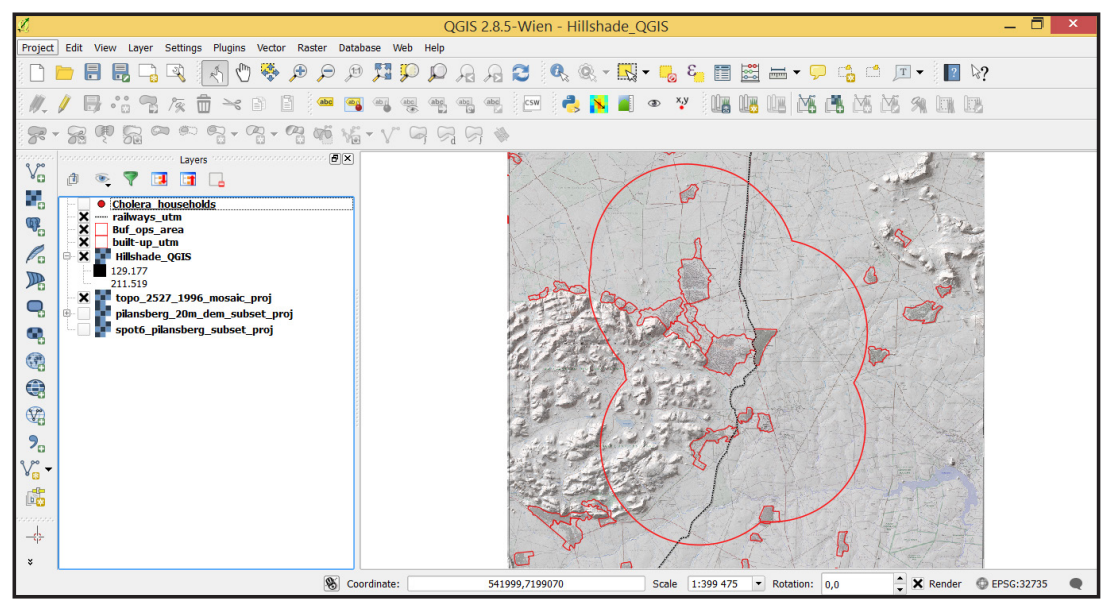

Figure 3: Terrain analysis - QGIS 


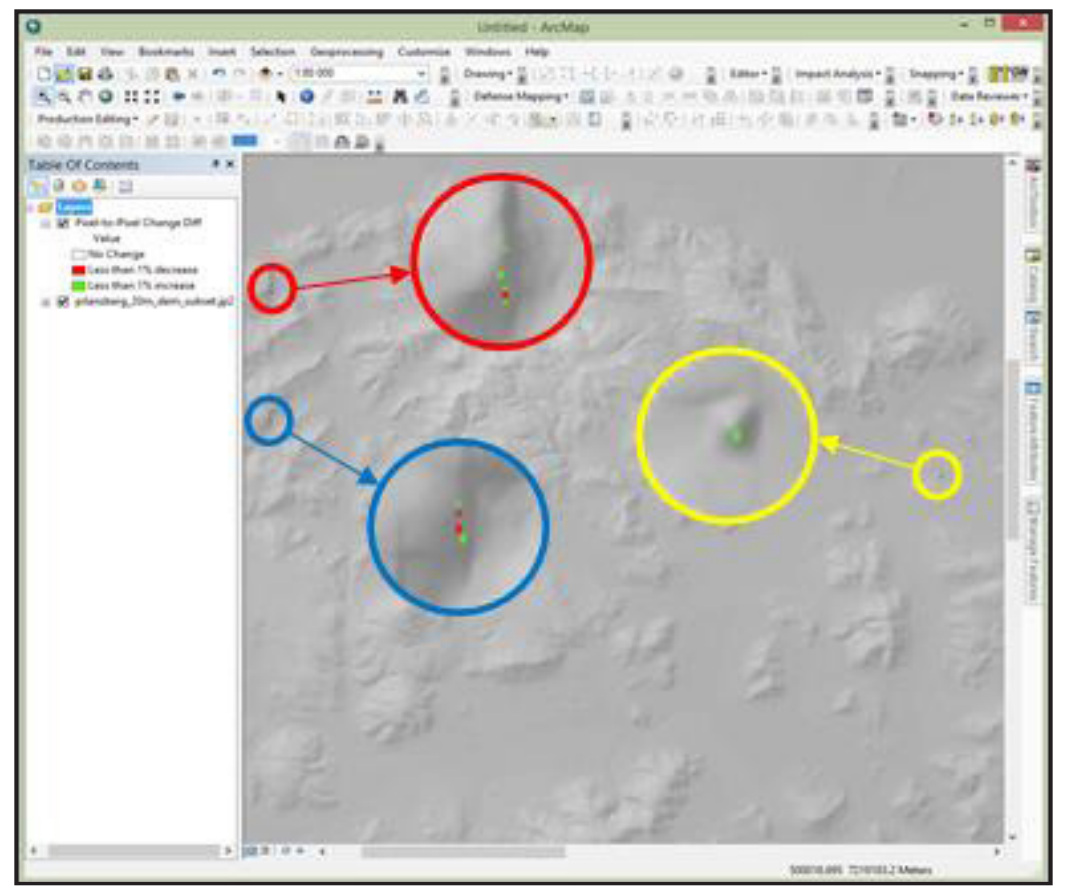

Figure 4: Hill shade analysis results comparison

A pixel-to-pixel comparison was done between the ArcGIS and QGIS outputs. It was determined that, for all practical purposes, the outputs of the two products were the same. The permissible input parameters for the illumination source were the same and therefore similar output results were achieved. However, very small differences did exist. These differences were so small that they were almost impossible to identify with the naked eye. These areas were therefore zoomed in on, and are indicated by means of the red, blue and yellow circles (see Figure 4). The comparison used the elevation source as a backdrop for orientation purposes. The pixel-to-pixel comparison shows 'green areas' that indicate less than $1 \%$ decrease changes from the ArcGIS result to the QGIS result. The 'red areas' indicate less than $1 \%$ increases. It is evident that the pixel value differences between these two software products were minimal, which is an indication that both these software products deliver good hill shading results that will be suitable for use during any military operation.

Test 2: Determining risk of cholera spread in the case of a flood

Flood lines were determined with raster-based flood simulation based on elevation. More sophisticated flood simulations and models exist, but the data for these are not always available for military operations, especially when assisting with relief operations in Africa. Flood lines were determined for one of the rivers in the area operations, namely the Mogwase River (see Figure 5). 
For this test, the current height value for the Mogwase River was specified as 1152 $\mathrm{m}$ above mean sea level. Flooded areas were determined should the river level rise to 1 $153 \mathrm{~m}, 1157 \mathrm{~m}$ and $1160 \mathrm{~m}$ respectively.

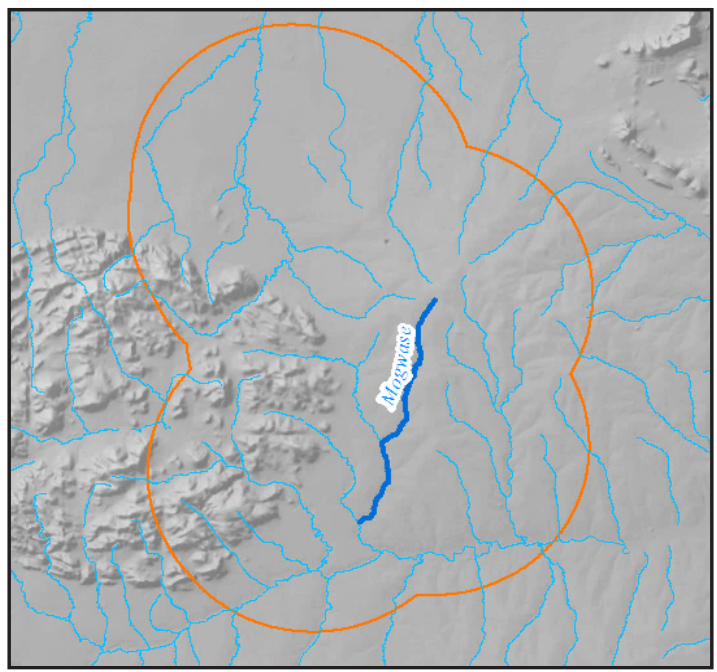

Figure 5: Mogwase River in relation to the rest of the area of operations

In ArcGIS, the raster calculator, one of the Map Algebra tools in the Spatial Analyst extension was used. The output is illustrated in Figure 6. In QGIS, the raster calculator under the Raster tab was used. The initial output is a single band greyscale image (see Figure 7), for which the styling can be adjusted for a better viewing experience (see Figure 8).

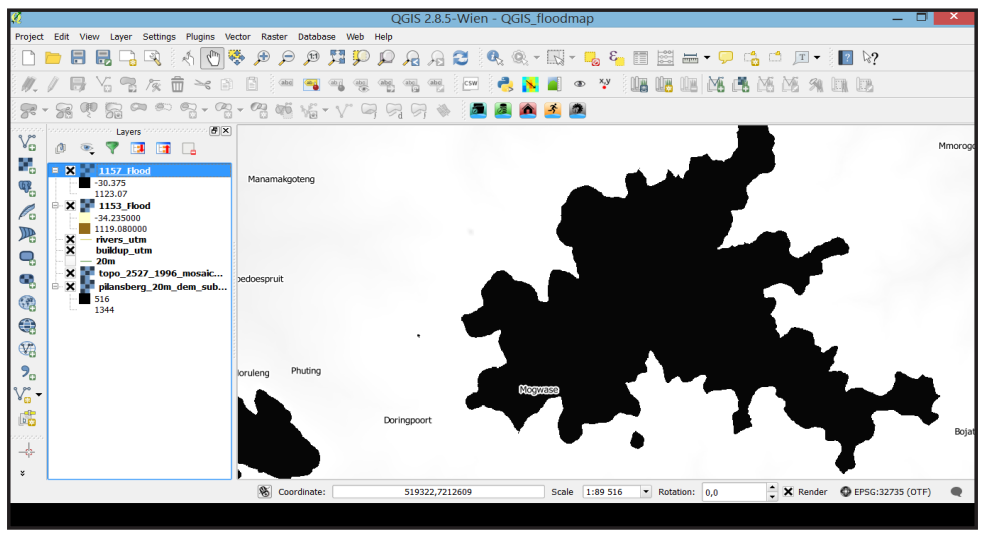

Figure 6: Flood simulation - ArcGIS 


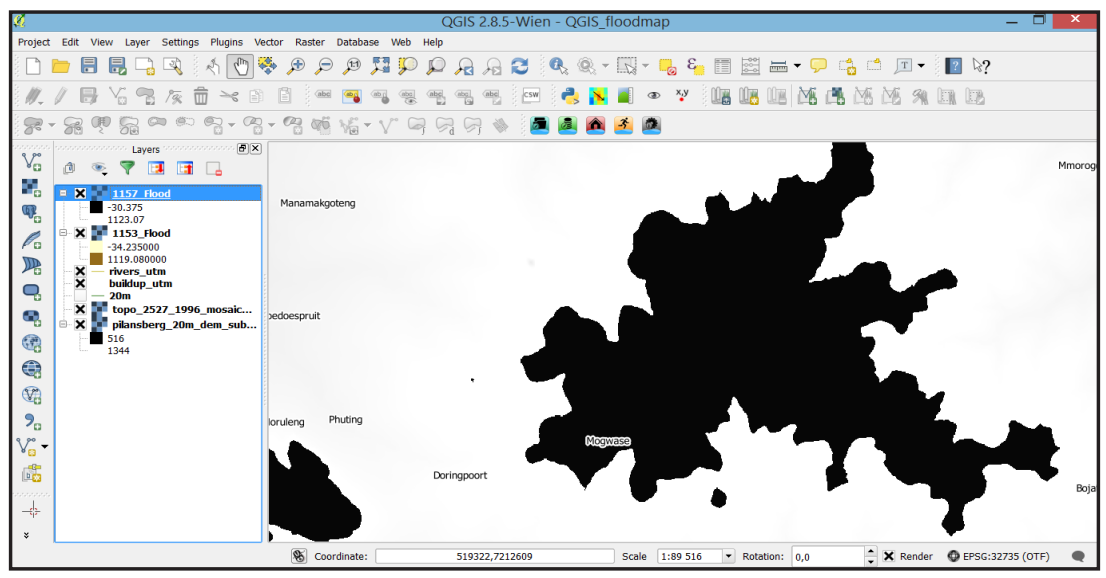

Figure 7: Flood simulation - QGIS

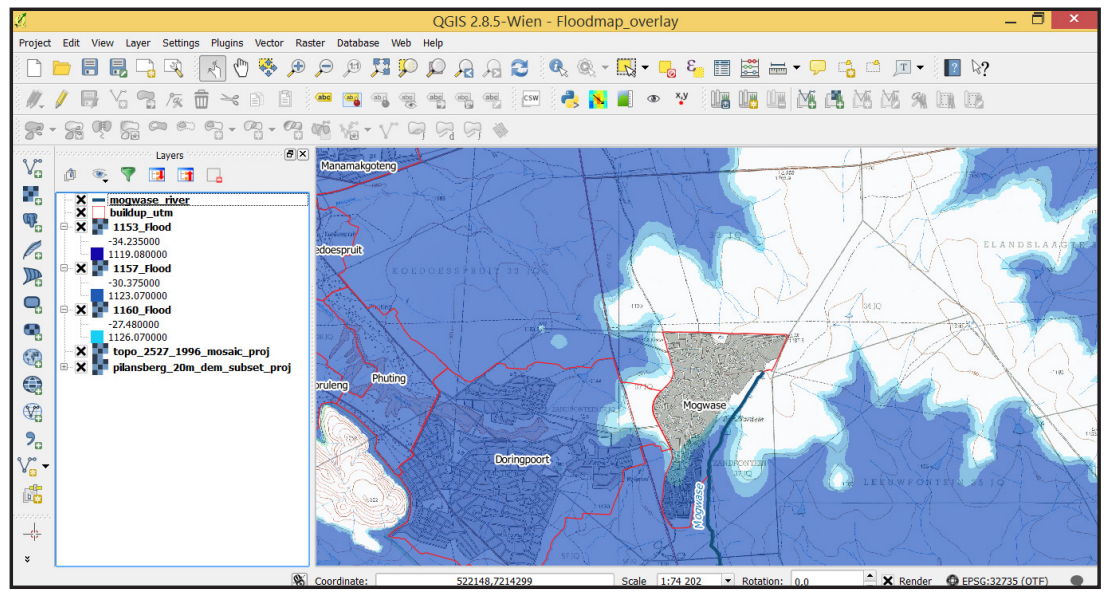

Figure 8: Flood simulation after adjusting the colours - QGIS

Figure 9 illustrates that the ArcGIS and QGIS outputs are alike. Closer inspection reveals minimal differences between the two outputs, illustrated in Figure 10: the ArcGIS outputs (light blue) are overlaid on top of the QGIS outputs (dark blue) to reveal that the QGIS layers cover a larger area than the ArcGIS layers. The average difference was measured to be $\sim 10 \mathrm{~m}$, which is not significant due to the size of the study area (approximately $935 \mathrm{~km}^{2}$ ). Therefore, it could be concluded that both products produced acceptable flood simulations that the commander might use to prevent cholera spreading during heavy rains and floods. 

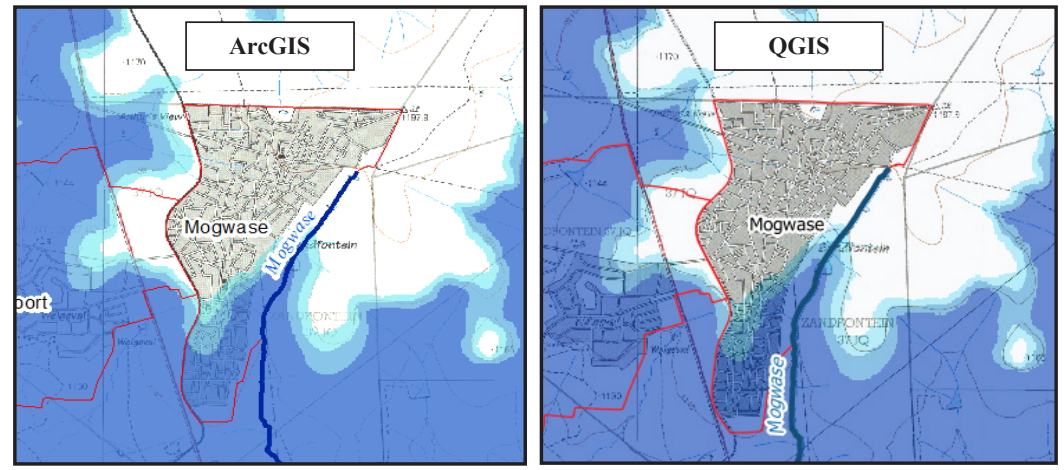

Figure 9: ArcGIS and QGIS flood simulation comparison
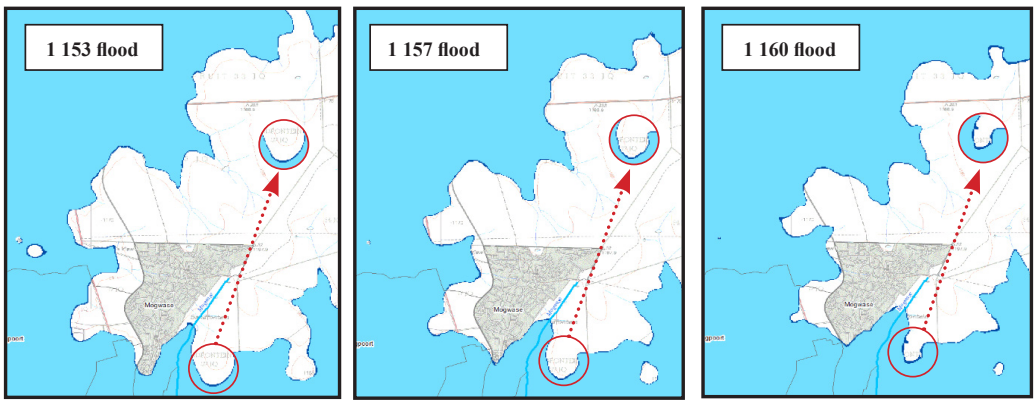

Figure 10: ArcGIS and QGIS flood simulation comparison

Test 3: Map of existing infrastructure

Maps of the transportation infrastructure, built-up areas, roads, rivers, railway lines and water bodies together with different points of interest (helipads, school, hospitals and police stations) were prepared. Symbols were styled to represent the various points of interest appropriately.

In ArcGIS (see Figure 11), styling of the points was made easy by the wide variety of symbols available in the symbol sets included with the installation. In the initial installation, the number of point symbols in the QGIS style library was limited. Additional point symbols in .SVG format were downloaded to extend the range of point symbols available in QGIS (see Figure 12). QGIS symbols are available from a wide variety of Internet sites at no cost.

The maps produced in both products could be used to identify locations for the operational headquarters (HQ), the medical post, entry and/or exit roadblocks and helicopter landing zones. 


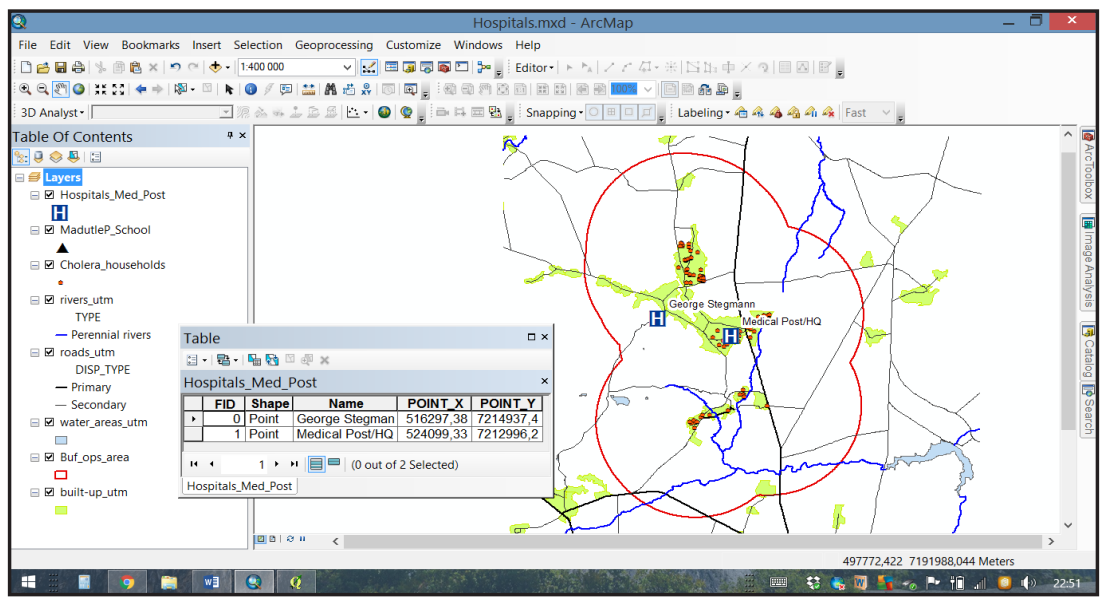

Figure 11: Map of hospitals in the area of operations - ArcGIS

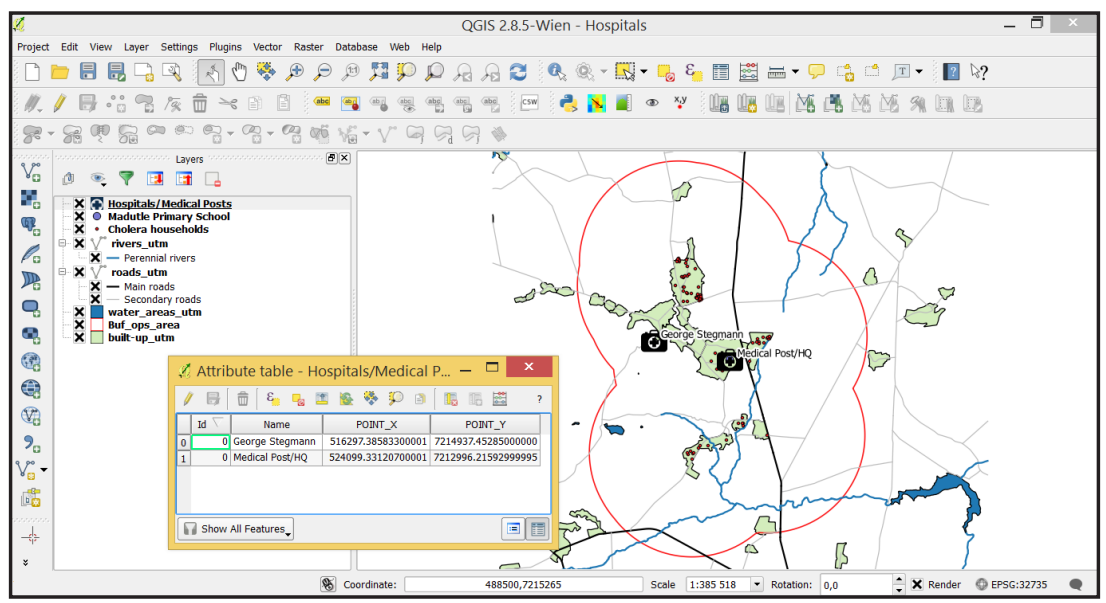

Figure 12: Map of hospitals in the area of operations - QGIS

Testing user-friendliness

User-friendliness is a very important aspect relating to GIS software acceptance since it determines the use of a product. ArcGIS and QGIS software was evaluated against the criteria as set out by Wallen to evaluate whether software products are userfriendly or not. The results were as follows: ${ }^{32}$

Simple to install - in order for the installation of software to be perceived as "simple to install", the process of installation should be easy to understand and well documented. ${ }^{33}$ In terms of the cholera use case specified, the installation of software had 
to form part of the pre-deployment preparation of the GIS team. The reasons for this were threefold.

- Internet access might be limited or not available in the area of operations (in this case the Pilanesberg area). Internet access is needed for the initial installation of both ArcGIS and QGIS. In the case of ArcGIS, the authorisation code should be obtained by means of the Internet. Where QGIS is concerned, Internet access is needed to download the complete software application initially. Once QGIS is downloaded, it can be saved on a storage device and installed at a later stage.

- Extensions (in ArcGIS) and the plugins and .SVG symbol files that QGIS needs will also have to be installed and activated before the deployment team leaves for the operation.

- $\quad$ Once the team arrives at the operational area, time cannot be wasted on the installation of software, extensions or plugins.

The researcher, on the same computer system, performed the process of installation for both ArcGIS and QGIS. The installation process of both software products adhered to the abovementioned criteria. The installation of both ArcGIS and QGIS was easy to understand and very well documented (online support or help in this regard is also available), and therefore both software products were evaluated as being 'simple to install'.

Easy to update - updates are also easy to perform. When a user does not update his or her software, he or she misses out on new features and the software can become less trustworthy and secure. ${ }^{34}$ In an operational scenario, all software updates will have to be done before the start of the operation - as far as possible. The update process in ArcGIS is fairly automated (the user follows the instructions in the license manager), unless the user wants to install the new version on a machine that is different from the one on which the previous version of ArcGIS 10.X was installed. In such a case, the previous product must first be de-authorised before authorising the new one. In QGIS, one can choose to uninstall the previous version and simply load the newest version. The user should take care to copy .SVG files when updates are being done on QGIS. Both these software products are therefore easy to update.

Intuitive - Wallen states, "software is only as good as its Graphical User Interface (GUI)." ${ }^{35},{ }^{36}$ People will have issues with using the software if the GUI is poorly executed. Wallen mentions that a well-designed GUI can often overcome a "less-thanfriendly underlying structure (or poor coding)", ${ }^{37}$ but it still means that the software must be working as expected. In both these software products, the GUI is very well designed. With regard to the basic functionality, such as adding and displaying data, zooming, panning and working with the attribute table, the two software products look and feel fairly similar. Concerning the more advanced functionality, such as the spatial and 3D analysis functions, the functionality may be located in different tabs and buttons and even use different extensions and plugins. In QGIS, the Plugin Manager can be used to inspect available plugins and to get a description of each. In ArcGIS, the relevant tool is easily located when using the Search function. The GUI in both software products can be customised to fit the user's need. Furthermore, saving functions are 
similar to the saving functions in other Microsoft software, which makes the GUIs more understandable to most people. Intuitiveness is a concept that is subjective in nature, and one that is influenced by the experience and knowledge of the GIS user. Based on Wallen's general description of intuitive, both these software products are evaluated as intuitive..$^{38}$ In terms of the specified use case, the only time the operation is affected by the GUI is when GIS operators are not familiar with the particular GUI. GIS operators must be fully trained on the particular software product, and in particular the GUI, in order to save time when completing a product for the operational commander.

Efficient - software should work as expected (be effective) and also be efficient. It must be able to work "seamlessly with underlying structures and subsystems". 39 Efficiency refers to the ability of the product to perform in the best manner with the least waste of time and effort. The efficiency and effectiveness of the software are also tied to 'intuitiveness'. In terms of the specified use case, no benchmark tests were done because of the many variables involved in efficiency; therefore, effectiveness was tested. Both ArcGIS and QGIS could produce all the required output products; both these software products were therefore evaluated as effective.

Pleasant, easy-to-navigate GUI - the GUI of the software must be both effective and intuitive. The primary function of the GUI should be to make the job easier for the end user. It does not help the end user if the design is trendy but makes for an unpleasant experience. ${ }^{40}$ In both ArcGIS and QGIS, the design of the GUI is trendy, and definitely makes the job easier for the end user. In both cases, the design of the buttons already gives the user an idea of what they are used for and, if the cursor hovers over a button, the name of that button is shown. As mentioned earlier, the GUIs of both these software products are customisable. In ArcGIS, this can be done by using the Customize dialog box. The user can choose to hide certain toolbars or even create a custom toolbar or menu. In QGIS, the Customization dialog box can be found under the Settings tab. In both these software products, the GUI is divided into five main areas, namely Menu Bar, Tool Bar, Map Legend, Map View and Status Bar) (see Figures 13 and 14 below).

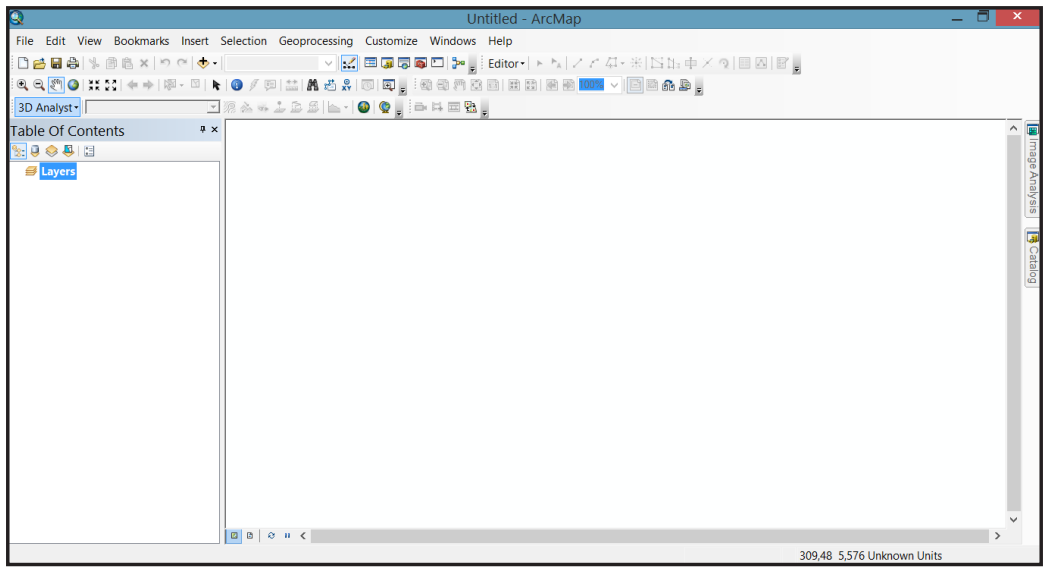

Figure 13: ArcMap GUI 


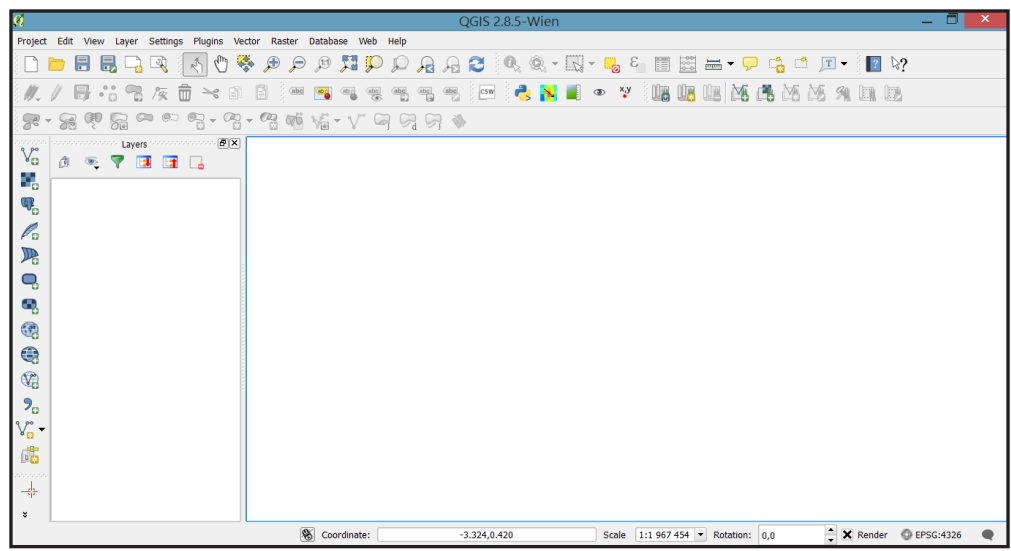

Figure 14: QGIS GUI

Easy to remove - the software removal process should be simple; otherwise, the software becomes a burden..$^{41}$ The uninstall process in both these software products is simple with no difficulties. In both cases an uninstall utility can be used to uninstall the software product. For both ArcGIS and QGIS, one can use the control panel, select Program and Features, navigate to the software product that needs to be uninstalled and choose to uninstall. A user can also inspect the program files on his or her computer, search for the software and delete it. As stated earlier, if the user plans to reuse .SVG symbols, he or she should remember to copy and save this folder before deleting QGIS. The uninstall process will not work differently given the specified use case. However, on SANDF computers, the installation and uninstalling of new software are done by a system administrator. The system administrator provides technical support and is the only person with the authority to alter the set-up of military computers, as is required by the security measures implemented in the SANDF.

Does not need third-party software - when a software product needs third-party software to keep it running, the computer can become exposed. This can generate a level of complication that average end users cannot handle. ${ }^{42}$ ArcGIS 10.2 needs Microsoft .NET Framework 3.5 SP1 as a minimum requirement for installation. ${ }^{43}$ This FOSS software product is, however, very easily obtainable, at no cost, on the Internet. QGIS does not need any third-party software to install and run.

Easy to troubleshoot - "No software is perfect". ${ }^{44}$ If there is a software problem, it is imperative that the end user should be able to call support to have the issue resolved. ${ }^{45}$ In terms of this criterion, the result may not be a simple 'yes' or 'no'. In terms of ArcGIS, troubleshooting certainly has a number of advantages. The user can access the Esri help files that are available to him or her, and if Internet access is available to the operation, the user can also access the Esri online support. Since the SANDF is paying the ArcGIS license fees, the operators will also be able to call Esri SA in such an event. If, however, the problem is coupled to a development issue in the software, the user might have to wait to see if it will be addressed when a newer version of the software is released. In terms of QGIS, the user manual can be downloaded before an operation to 
assist with questions that might arise. If Internet access is available during the operation, GIS operators can also pose their question to the active QGIS support mailing list. The members of the mailing list are not required to answer any questions posted. In addition, if a bug in the software is reported, developers can decide whether to fix it or to develop additional functionality. As a result, the QGIS team encourages commercial support contracts with third parties. The QGIS website contains a list of such commercial support contractors with links to their respective websites. These companies offer QGIS product support and services to their clients.

Adheres to standards - standards are important in order to make interconnectivity between applications or hardware easy. Complications develop when developers do not adhere to standards. In such circumstances, end users will experience difficulty because their tools will not be able to communicate with other tools that do comply with the standards. ${ }^{46}$ Both QGIS and ArcGIS supported the relevant standards needed to complete the tests in this use case (for example, standards for shapefiles, GeoTIFF files and supporting the feature model).

Effective error handling - the manner in which software handles a problem when it occurs is significant. The software must be able to warn the users and let them know what they can do to solve it. The software should not only 'time out' and close. ${ }^{47}$ Considering the cholera use case and the tests that were run using both these software products, neither of them ever 'timed out' or 'closed'. In cases where the researcher did not complete a required field in a dialog box, the software guided the researcher to the problem area.

\section{Analyses of user-friendliness as compared between ArcGIS and QGIS}

Ten criteria were compared in order to determine the user-friendliness of both ArcGIS and QGIS. All 10 criteria were measured against the specified cholera use case. Some of the criteria were general in nature and not only true for this particular operation. Some of the criteria were also very closely related to one another. These were 'pleasant, easy-to-navigate GUI', 'intuitive' and 'efficient' as well as 'simple to install' and 'easy to remove'. However, in terms of the criteria 'does not need third-party software', ArcGIS does need third-party software for its installation and the like.

It was found that, although the GIS operator supporting an operation - such as the one specified in the use case - will definitely have to note some of the details mentioned in the paragraphs above (such as budgeting for commercial support for QGIS), both ArcGIS and QGIS can generally be considered to be user-friendly. The ArcGIS requirement for software, as stated above is also not considered to be a limiting factor in terms of the user-friendliness of the software, since this software is freely available to users.

\section{Testing costs}

The cost factor was one of the main reasons for conducting this research project. Cost factors are not compared in military operations in general, but only in using the SANDF as a use case to compare costs. QGIS is subject to the General Public License (GPL), and it is an open source GIS product that can be installed on as many workstations as needed in order to support the cholera operation, as specified in the use case. All plugins that will be needed to complete the products, as specified in the use case, can also be installed at no cost (except costs involved in obtaining Internet access). 
In terms of costs for QGIS training, the SANDF developed an introductory course. For more advanced courses, the SANDF can attend courses at commercial contractors, such as Kartoza, as specified on the QGIS website. According to the course outcomes specified on the Kartoza website, ${ }^{48}$ the five-day course, Advanced GIS with FOSS, will be suitable in order to complete the tasks as specified in the use case. There are also opportunities for free online courses such as the one being offered on the Canvas website. ${ }^{49}$ Canvas is an open-source learning management system.

In terms of QGIS, the researcher suggests that military institutions should include the costs that are needed to obtain extra commercial support during their initial budgeting process for an operation in case this type of support is needed during the operation.

In terms of ArcGIS, the researcher acknowledges the fact that Esri SA currently has an end user license agreement (EULA) with the SANDF, which means that licenses for an operation such as the one mentioned in the use case will be supplied to the SANDF at a special discounted rate. The exact details and amounts regarding this agreement cannot be disclosed in this article, due to confidentiality clause in the client agreement.

In terms of existing training on ArcGIS, the researcher also acknowledges the fact that current GIS operators in the SANDF have, through the years, done quite a number of courses both in the SANDF itself and at Esri SA. The current knowledge base of present-day GIS operators in the SANDF with regard to ArcGIS is therefore quite extensive. New members are continuously joining this pool of GIS operators, which will require them to attend the same GIS training on the various GIS software. The SANDF itself offers the basic introductory course, and various free online courses are also being offered to ArcGIS users. In terms of the requirements for this use case, members will at least have to do courses at Esri SA up to the advanced level, performing analysis, designing maps with ArcGIS and working with rasters. In addition, members will have to do courses relating to the extensions Spatial analyst and 3D analyst. These courses provide operators with basic as well as advanced knowledge of the software, enabling them to perform basic tasks, map compositions and editing, as well as some more advanced spatial analysis functionalities and knowledge relating to the extensions that were used during this use case, namely Spatial analyst and 3D analyst.

\section{Analyses of costs as compared between ArcGIS and QGIS}

In terms of the costs involved in acquiring software, as well as the costs for some of the training requirements, QGIS has a definite advantage over ArcGIS. In terms of the use case, the ArcGIS license and extensions needed, far exceeds the amount needed for QGIS. However, once the initial ArcGIS purchase is made, the support when troubleshooting occurs will be included in the EULA as part of the subscription fees.

\section{Discussion and conclusion}

The results in the previous sections showed that QGIS can be used to produce outputs equivalent to those prepared with the baseline product, ArcGIS. In some cases, it was necessary to configure the QGIS output for an optimal viewing experience, but this is also the case for some of the ArcGIS outputs. Both products are easy to use, but require training and an understanding of the principles behind geographic information and mapping. More in-depth user studies may point out significant differences in the usability of the software, but that was not the goal of the current study. Proprietary 
software vendors sometimes include exclusive technical support and training in the cost of the software licenses, regardless of whether this is used or not. With open source software, one is free to choose if and by whom technical support and training are provided. Furthermore, open source software can be installed on any number of desktops without going through a lengthy budgeting and procurement cycle. This is especially useful when GIS operations have to be expanded at short notice and when funds are limited.

Based on the results presented in this article, one can conclude that open source GIS software can be deployed successfully for military operations. This opens a world of alternative possibilities to the military. Institutions that would normally be deprived of GIS because of costs now have access to large selection tools. Open source geospatial technologies are available for requirements beyond those identified for the use case in this study, extending to field data collection, crowdsourcing, visualisation, spatial database management systems, and software stacks for web-based systems using clientserver architectures. ${ }^{50},{ }^{51},{ }^{52}$

Nevertheless, adopting open source GIS should not be based solely on technical merit and the no-cost implication. Open source software products should be evaluated on a par with proprietary software in terms of their technical features, standard compatibility, reliability, ease of use, documentation, technical support, customisability and extensibility, costs of training, technical support and management requirements, such as budgeting and long-term maintainability. ${ }^{53,},{ }^{54}, 55$

A limitation of this study was that the effectiveness of the GIS software to handle large data sets was not tested. The data sets used during this study were subsets of the study area. In the age of big geospatial data, the manner in which these GIS software products handle large volumes of data needs to be considered in many, if not most, use cases. This study compared two specific software products. The results might have been different if alternative open source and/or proprietary products had been used. Finally, this study did not assess the attitude of users towards FOSS. The results show that the technical functionality of open source is comparable to a proprietary solution but the question remains how users feel about using QGIS. This could be done in further work, as well as a user study to assess the usability (user interface) of the products.

Worldwide, the use of open source GIS is growing, ${ }^{56}$ and it is likely that militaries will follow suit as staff are gaining knowledge and experience to the same levels they have in proprietary GIS products. Currently, the United Nations Open GIS Initiative ${ }^{57}$ is leading the way by identifying and developing open source geospatial solutions that meet the requirements of United Nations operations. In the military geospatial solutions is a force multiplier which is described as the "capability that, when added to and employed by a combat force, significantly increases the combat potential of that force and thus enhances the probability of successful mission accomplishment" ${ }^{58}$ Open source GIS has the potential to be a force multiplier in the military!

\section{Acknowledgments}

Susan Henrico's master's research was financially supported by the South African National Defence Force, Defence Intelligence. 


\section{ENDNOTES}

${ }^{1}$ Dr Susan Henrico is a lecturer in the Department of Strategic Studies in the Faculty of Military Science of Stellenbosch University. She recently completed her doctoral studies with the Department of Geography, Geoinformatics and Meteorology, University of Pretoria, South Africa.

${ }^{2}$ Prof Serena Coetzee is the Head of the Department of Geography, Geoinformatics and Meteorology at the University of Pretoria, South Africa. She is also the Director of the Centre for Geoinformation Science.

${ }^{3}$ Dr Antony Cooper is a Principal Researcher in the Smart Places Cluster at the CSIR in Pretoria, South Africa. He is an Extraordinary Lecturer at the University of Pretoria and a member of the statutory body, the Committee for Spatial Information (CSI). He is also a Registered Professional GISc Practitioner (PGP).

${ }^{4} \mathrm{~K}$ Lodi, H Smit \& G Ayirebi. "Terrain analysis in the course curricula of the South African Army Engineer Corps". Scientia Militaria 42. 2014. 102-121.

${ }^{5} \mathrm{~T}$ Neethling. "Military forces and non-traditional military roles: Assessing post-Cold War developments and considering some implications for the SANDF". Journal for Contemporary History 27/1. 2002. 1-18.

${ }^{6}$ Lodi et al. op. cit.

${ }^{7}$ IM Datz. Military operations under special conditions of terrain and weather. New Delhi, India: Lancer Publishers, 2008.

${ }^{8} \mathrm{G}$ Ünal \& T Mustafa. "Terrain analysis for military operations using geographic information systems". Paper presented at the International Symposium on GIS, Istanbul, 2002.

${ }^{9}$ FP Donnelly. "Evaluating open source GIS for libraries". Library Hi Tech 28/1. 2010. $131-151$.

${ }^{10} \mathrm{R}$ Moreno-Sanchez. "Guest editorial. Free and open source software for geospatial applications (FOSS4G): A mature alternative in the geotechnologies arena". Transactions in GIS 16/2. 2012. 81-88.

${ }^{11}$ MA Brovelli, M Minghini, R Moreno-Sanchez \& R Oliveira. "Free and open source software for geospatial applications (FOSS4G) to support Future Earth". International Journal of Digital Earth 10/4. 2017. 386-404.

${ }^{12}$ J Jacobs. "Illustrating the levels of war - Operation Zitadelle (Kursk), 5-14 July 1943: A case study". Scientia Militaria 33/2. 2005. 78-94.

${ }^{13}$ AM MacEachren, A Robinson, S Hopper, S. Gardner, R Murray, M Gahegan \& E Hetzler. "Visualizing geospatial information uncertainty: What we know and what we need to know". Cartography and Geographic Information Science 32/3. 2005. 139-160.

${ }^{14}$ EJ Palka, FA Galgano, JC Malinowski, EW Anderson, JV Minghi, RW Dixon \& RG Bailey. The scope of military geography: Across the spectrum from peacetime to war. London, United Kingdom: McGraw-Hill, 2000.

${ }^{15}$ D Swann. "Military applications of GIS". International Journal of Geographical Information Systems 2/2. 1999. 889-899. 
${ }^{16}$ B Tuner. Information operations in strategic, operational, and tactical levels of war: A balanced systematic approach. Monterey, CA: Naval Postgraduate School, 2003.

${ }^{17}$ QGIS. A free and open source geographic information system. 2020. $<$ http://www.qgis.org $>$ Accessed on 21 June 2020.

${ }^{18}$ Esri. Technical support. 2017. $<$ https://support.esri.com/en/products/desktop/arcgis-desktop/arcmap/10-2-2> Accessed on 13 March 2017.

${ }^{19}$ C Dempsey. "QGIS versus ArcGIS”. GIS Lounge. 2012. < $\underline{\text { https://www.gislounge.com/ }}$ qgis-versus-arcgis/> Accessed on 8 August 2016.

${ }^{20} \mathrm{~N}$ Duggan. "QGIS v ArcGIS”. xyHt. 2015.

$<$ http://www.xyht.com/spatial-itgis/qgis-V-arcgis/> Accessed on 19 September 2016.

${ }^{21}$ GIS Geography. "27 differences between ArcGIS and QGIS: The most epic GIS software battle in GIS history". 2016. < http://gisgeography.com/qgisarcgis-differences/> Accessed on 9 June 2016.

${ }^{22}$ Humitarian OpenStreetMap Team. OpenStreetMap \& QGIS training for geology students in Bamako, Mali. 2020. <https://www.hotosm.org/> Accessed on 16 February 2020.

${ }^{23}$ SJ Henrico, S Coetzee \& AK Cooper. "Analysing the practical feasibility of FOSSGIS in military operations: A cholera outbreak use case". Paper presented at the Free and Open Source Software for Geospatial (FOSS4G) Conference, Bonn, Germany, 2016.

${ }^{24}$ TomTom. About Us. 2016. https://www.tomtom.com/en_za/ Accessed on 23 May 2016

${ }^{25}$ National Geo-Spatial Information (NGI). About NGI. 2016. http://www.ngi.gov.za/ Accessed on 23 May 2016.

${ }^{26}$ Dempsey op. cit.

${ }^{27}$ WebMD. "Cholera". 2016. < http://www.webmd.com/a-to-Z-guides/cholera-faq $>$ Accessed on 25 October 2016.

${ }^{28}$ JM Davids. Personal communication, 12 May 2015.

${ }^{29}$ AFV van Niekerk. Personal communication, 4 September 2015.

${ }^{30}$ JD Venter. Personal communication, 26 May 2015.

${ }^{31}$ AC Wylie. Personal communication, 5 October 2015.

${ }^{32} \mathrm{~J}$ Wallen. "10 things that make software user-friendly". TechRepublic. 2010. $<$ http://www.techrepublic.com/blog/10-things/10-things-that-make-softwareuser-friendly/> Accessed on 26 October 2016.

${ }^{33}$ Ibid.

${ }^{34}$ Ibid.

${ }^{35}$ Ibid.

${ }^{36} \mathrm{Z}$ Abdellah, A AmineArrahmane \& J Fatima. "Factors affecting adoption of FLOSS ERP system by SMEs f directors and managers in developing countries using UTAUT2, SEM and R". Paper presented at the 4th IEEE International Colloquium on Information Science and Technology (CiSt), Morocco, Spain, 2016.

${ }^{37}$ Wallen op. cit. 
${ }^{38}$ Ibid.

${ }^{39}$ Ibid.

${ }^{40}$ Ibid.

${ }^{41}$ Ibid.

${ }^{42}$ Ibid.

${ }^{43}$ Esri. "ArcGIS 10.3.x for desktop system requirements". 2016.

$<\underline{\text { http://desktop.arcgis.com/en/arcmap/10.3/get-started/system- }}$

requirements/arcgis-desktop-system-requirements.htm\#esri

section1_04af56ec09234d5aa5a5456c8a47a1bf $>$ Accessed on 30 October 2016.

${ }^{44}$ Wallen op. cit.

${ }^{45}$ Ibid.

${ }^{46}$ Ibid.

${ }^{47}$ Ibid.

${ }^{48}$ Ibid.

${ }^{49}$ CANVAS. Because the Best Educators Never Stop Learning. 2017. < https://www. canvas.net/> Accessed 17 June 2017.

${ }^{50}$ Moreno-Sanchez op. cit.

${ }^{51}$ GM Lingaraju, P Nithiarasu, M Kusuma \& RM Gowda. "Real-time interactive steerable scientific visualisation of free surface flow in the context of synthetic vision". Defence Science Journal 61/4. 2011. 299-305.

${ }^{52}$ S Steiniger \& AJ Hunter. "Free and open source GIS software for building a spatial data infrastructure". In Bocher, E \& Neteler, M (eds). Geospatial free and open source software in the 21st century: Lecture notes in Geoinformation and Cartography. Berlin: Springer, 2012.

${ }^{53} \mathrm{H}$ Wang \& C Wang. "Open source software adoption: A status report”. IEEE Software 18/2. 2001. 90-95.

${ }^{54} \mathrm{~K}$ Ven, J Verelst \& H Mannaert. “Should you adopt open source software?". IEEE Software 25/3. 2008. 54-59.

${ }^{55}$ T Sutton. "Deciding between FOSSGIS and proprietary software in the enterprise". GIS Professional. February 2018. 18-19.

${ }^{56}$ Brovelli et al. op. cit.

${ }^{57}$ UN Open GIS. UN Open GIS Initiative. 2019. $<\underline{\text { http://unopengis.org/> Accessed on } 16}$ August 2019.

58 JP Abizad. Joint Tactics, Techniques, and Procedures for Joint Special Operations Task Force Operations. Joint Publication 3-05.1. Washington, DC: Office of the Chairman of the Joint Chiefs of Staff, 2001. [Check wording] 